\title{
Spontaneous Rituals as a Design Model for CCI Platforms
}

\section{Elena Alfaro}

Pontificia Universidad Católica de Chile

elalfaro@uc.cl

ORCID 0000-0002-4002-9815

\section{Laura Succini}

Alma Mater Studiorum

— Università di Bologna

laura.succini@unibo.it

ORCID 0000-0003-2662-8413

\author{
Pietro Gamberini \\ Università degli Studi \\ di Modena e Reggio Emilia \\ pietro.gamberini@unimore.it \\ ORCID 0000-0003-1714-787X
}

\section{Abstract}

The research investigates the sector of the Cultural and Creative Industries, with a focus on their relation with identity, communities and territories.

In contemporary times, a territorial disintegration has been observed, underlay by the after covid-19, which highlights an increasing tendency towards the digitization of processes.

Within these dynamics, we can see how digital collaborative models dedicated to $\mathrm{CCl}$ still have considerable scope for design.

This research proposes an analytical method that applies an advanced design approach to tools primarily used in anthropology. Through a morphological analysis of some selected spontaneous rituals, the research identifies categories and subcategories of design interest. The impact of these categories are then applied to the platforms dedicated to $\mathrm{CCl}$ with the aim of turning them into digital spaces capable of activating a closer collaboration between the actors and local communities involved.

\section{Keywords}

Advanced Design

Spontaneous rituals

Design and ritual

Platform

Cultural and Creative Industries 


\section{$\mathrm{CCl}$ and Collaborative Practices}

The economic and social system in which we live is structured and complex, and Covid-19 has highlighted the fragility and peculiarities of the territorial ecosystems in which we operate. These events have redefined the systems of relations between people and territory; they have also suggested different points of view regarding spatial, productive, and relational proximity. On one hand, proximity relations are reactivated, knowledge, skills and spontaneous collaboration methods are rediscovered; on the other hand, a spatial and temporal dimension is activated, defined within a "virtual" container, where collaboration and knowledge processes and tools are enabled by digital systems which, within neutral environments, establish dialogues between people, the project, and the territory. This latter system changes the repertory of behavior between the actors and the space in which it is inserted, intervening at a social, experiential and knowledge level.

In the tangible forms of socialization created through shared experience (Nonaka, 1994, p. 19) the processes lead to the generation of a form of tacit knowledge based on the sharing of time, emotions inherent in experiences between people (Santoro et al., 2020). It can be referred to as a relationship characterized by reciprocity and intangible exchange/donation (Sedini, 2018, p. 210). A system of relationships that due to its structure (social, cultural) lasts over time.

The processes of socialization within the territory activate not only systems of spatial and temporal proximity, but also of "cognitive, organizational, social, institutional nature (Boschma, 2005)" (Sedini, 2018, p. 210).

Society is currently going through a phenomenon of transition from the real to the virtual in which "Communities of interest, practice or action" (Bortolotto, 2010, p. 360) are formed on the basis of a proximity grounded on common culture, interests and values, are capable of creating international connections.

This leads to the question of how collaborative/collective practices within a digital dimension can maintain links/rituals/dialogues involving all the actors of the territory, encouraging a feeling of cultural and social cohesion, and developing systems of knowledge, enhancement and belonging.

Within an economic, social post-pandemic vision the Creative Cultural Industries (CCl) framework is an interesting context in which this phenomenon can be investigated; it is in fact:

- $\quad$ characterized by social and economic processes linked to a narrative of intrinsic meanings of a territory (Lerro \& Schiuma, 2014);

- $\quad$ articulated by multidimensional and multi-verse relationships and collaborative approaches involving all actors and the territorial capital, in a system that we could define quintuple helix (Carayannis et al., 2012). 
A context that develops both physical and digital forms of collectivity, that continuously connects tradition and technology and that - due to its conformation within the territorial ecosystem is oriented towards a production of value based on proximity and on creative property and local know-how "thus generating knowledge spillovers" (Béraud et al., 2012, p. 92).

On the one hand, $\mathrm{CCl}$ activate models and dialogues between local entities; on the other, they establish regional, national, and transnational relations and synergies. They are part of a fluid system, whose boundaries are continually reshaped in accordance with the peculiarities and characteristics of each territory (UNDP \& UNESCO, 2013), where collaborative processes seek projects that are flexible, implementable but durable over time, to ensure a continuous responsible innovation.

The $\mathrm{CCl}$ context is very broad, featuring different types of creative people, sectors, and public and private forms of enterprise. The systems of aggregation and relationship that are created are multi-scale (Béraud et al., 2012, p. 83).

Aggregative systems, which manifest in a real space, making however more and more of digital collaborative tools, such as platforms, with the aim of creating digital communities. A virtual network that less than others, succeed in creating that emotional tension between communities and their feeling of belonging.

\section{Spontaneous Collective Practices}

A socialization process able to involve different levels of the territory are the spontaneous collective practices: ritual processes related to the tradition of territorial ecosystem.

These collective practices allow the creation or preservation of a collective value, whose outcomes of affect the whole group or community and aim at a common material or immaterial purpose. Such practices, in collaboration with heterogeneous entities, become carriers of meaning in which the approach to the individual's reality is absorbed and at the same time changed within the process itself.

The ritual relates to territoriality, sense of community, creativity, recreation, transversality, individuality, collectivity (Pils \& Trocchianesi, 2017).

For these reasons, collective practices characterized by the ritual aspect have been identified as a system to be observed and from which to take factors and aspects to be integrated within the forms of aggregation of $\mathrm{CCl}$. 


\section{Research Focus}

Contextualized in a broader issue such as the $\mathrm{CCl}$, this research proposes an investigation on phenomena of spontaneous and creative collaboration whose traces can be found in several sectors, such as manufacturing, spontaneous design (Scodeller, 2017), or intertwined to systems that strengthen territorial identities, spontaneous rituals.

In this second case, the collaborative connection between involved actors appears easier to be explored as evidenced by the narration of an entire territory that within this process finds the way to cyclically regenerate its identity.

If collective practices and their rituals are read through design, in the sense of "observing in order to innovate" (Pils \& Trocchianesi, 2017, p. 19) it is possible to transpose their main elements into a new grammar of shared actions and practices that can be applied within platforms that make $\mathrm{CCl}$ interact. The aim is to transform these digital services into "cultural phenomena, capable of aggregating communities in different spaces and times [...] bringing them together in what can be defined as a ritual space-time." (Pils \& Trocchianesi, 2017, p. 57).

\section{Design Approach}

The case studies reviewed come from geographically distant territorial ecosystems with very strong local identities; this shows that creativity, culture and innovation are influenced by local properties, but also that what can lead to innovation and growth of $\mathrm{CCl}$ is the social and community process that is established between the actors that interact in these realities.

Due to territorial proximity and ease of access to direct sources, the choice of rituals fell on the Carrera Autopodistica of Castel San Pietro Terme, Italy and the Andean Carnival of Arica, Chile. These events are characterized by a strong vitality. The two Mise-en-Scène show high-level design qualities that have evolved over time in synergy with the territories and have withstood the generational change as proven by their longevity.

The two rituals were subjected to an anthropologically derived morphological decomposition aimed at highlighting the components of Locus (spatial and temporal dimensions) and Habitus (the communicating part of body, objects, and behaviors) (Pils \& Trocchianesi, 2017, p. 103).

Through a design-driven approach, the categories isolated in the analysis were used to read three platforms dedicated to $\mathrm{CCl}$.

The application of the ritual model to the platforms might not find full adherence in the categories, however it allows to compare a social process of virtuous collaboration with a growing digital phenomenon with significant margins of innovation in the light of the territorial fragmentation of processes and relationships. 
Spontaneous rituals are moments in which multiple flows of overlapping and interconnected relationship and collaboration interact; the human being is suspended in a network of meanings that himself has woven (Geertz, 1973).

Cases such as the Carnaval of Arica or the Carrera of Castel San Pietro Terme are valid examples of contexts that bring back the etymological value of "weaving-together", from the Latin contexĕre. Each member of the extended community, whether directly involved or simply a spectator, feels part of something else.

\section{Carrera Autopodistica}

The Carrera Autopodistica is a competition that has been held in the town of Castel San Pietro Terme, in the metropolitan area of Bologna, Italy, since 1954. The name originates from the famous Carrera Panamericana, which was run in those years, but the form is completely different: a four-wheeled car is pushed by a team of runners along the city streets with the aim of arriving before the opponents (Dal Fiume, 2003). The Carrera is run once a year in the context of the Sagra della braciola and in the large aggregator of events called Settembre Castellano, which aims to promote tourism and local products.

During the year, the teams who participate in the Carrera design and build the cars they will use in the competition. From its origins to the present day, the cars have evolved from compositions of aircraft scrap to technological objects in carbon fibre.

The continuous search for technical solutions, the rivalry, and the declination of the Carrera on several targets have attracted thousands of spectators for more than 60 years.

Carnaval Andino, Inti Ch'amampi, con la Fuerza del Sol (Andean Carnival, Inti Ch'amampi, with the Strength of the Sun)

The Carnaval Andino, Inti Ch'amampi, con la Fuerza del Sol, is an international three-day event held in the city of Arica, in the Region of Arica and Parinacota in northern Chile, which brings together more than 16,000 dancers ${ }^{1}$ who perform dances representative of the Andean culture, mainly of the Aymara people and to a lesser extent Afro-descendants, present in this territory. Organised in comparsas from Chile, Bolivia, Peru, Brazil and Argentina, they compete in categories, in a ritual whose daily attendance is estimated by the organizers at 100,000 people.

At the beginning of the 21 st century, two parades used to be held to showcase these events: Inti Ch'amampi, and Con la fuerza del Sol, "In 2005, in a union between these groups and the Municipality of Arica, it was decided to hold the Carnaval Andino Internacional con la Fuerza del Sol Inti Ch'amampi" (Casals et al., 2018). 
The El Carnaval Andino con la Fuerza del Sol, as we know it today, is an annual event that takes place during a weekend in which groups dance while the musicians accompany them in the historic center of the city. During their performance, they are evaluated by a jury. The celebration schedule in Arica includes previous stages such as the "convite", a week before the beginning of the Carnival, when the general rehearsal takes place.

On the first day of the celebration, each comparsa presents its $\tilde{N} u s t a$ and $/ n c a^{2}$ and the ancestral ceremony or pawa, according to Andean tradition, takes place. The organization of the Andean Carnival, a festival that is not linked to agricultural cycles or patron saint festivals, encourages traditional practices that allow "linking this festival to the cyclical sense of gratitude to the earth" (Chamorro, 2013).

The Andean Carnival is a celebration that takes place in urban and coastal public spaces and whose organization involves an organizing committee, composed of the Municipality of Arica, the Confraternity of Andean Dances Inti Ch'amampi and the Federation of Andean Dances Kimsa Suyu, who define in a detailed document the Bases of Participation of each of the annual meetings. The competition is one of the main features of the Andean Carnival, which awards cash prizes to the winners who compete in categories divided into International Dances and Danzas de Rescate Local ${ }^{3}$.

The money prize is a recognition that allows to partially cover the expenses that each comparsa incurs annually, mainly to pay for the costumes. The costume changes every year, and the design is made by the members of the comparsa, who then have it tailored.

We mustn't forget that in the Carnaval Andino, the dances of the Andean culture are presented, a culture that overlaps the political boundaries of the countries that border the city of Arica and which include not only Chile but also Bolivia and Peru ${ }^{4}$. The comparsas are groups made up of men and women of different ages. These groups meet and rehearse periodically in spaces provided by the partners or in public spaces. Fig. 1
2

This is the presentation of the king and queen of each competing group. The ñustas "are girls who embody the most essential principles for the groups (Chamorro 2010).

3

It is also possible to exhibit only and not to compete.

4

To understand the relationship between countries and people in the territory, as well as the recreation of their customs, Choque Cáceres proposes an analysis based on the transnational concept. (Choque-Caseres, 2019). 


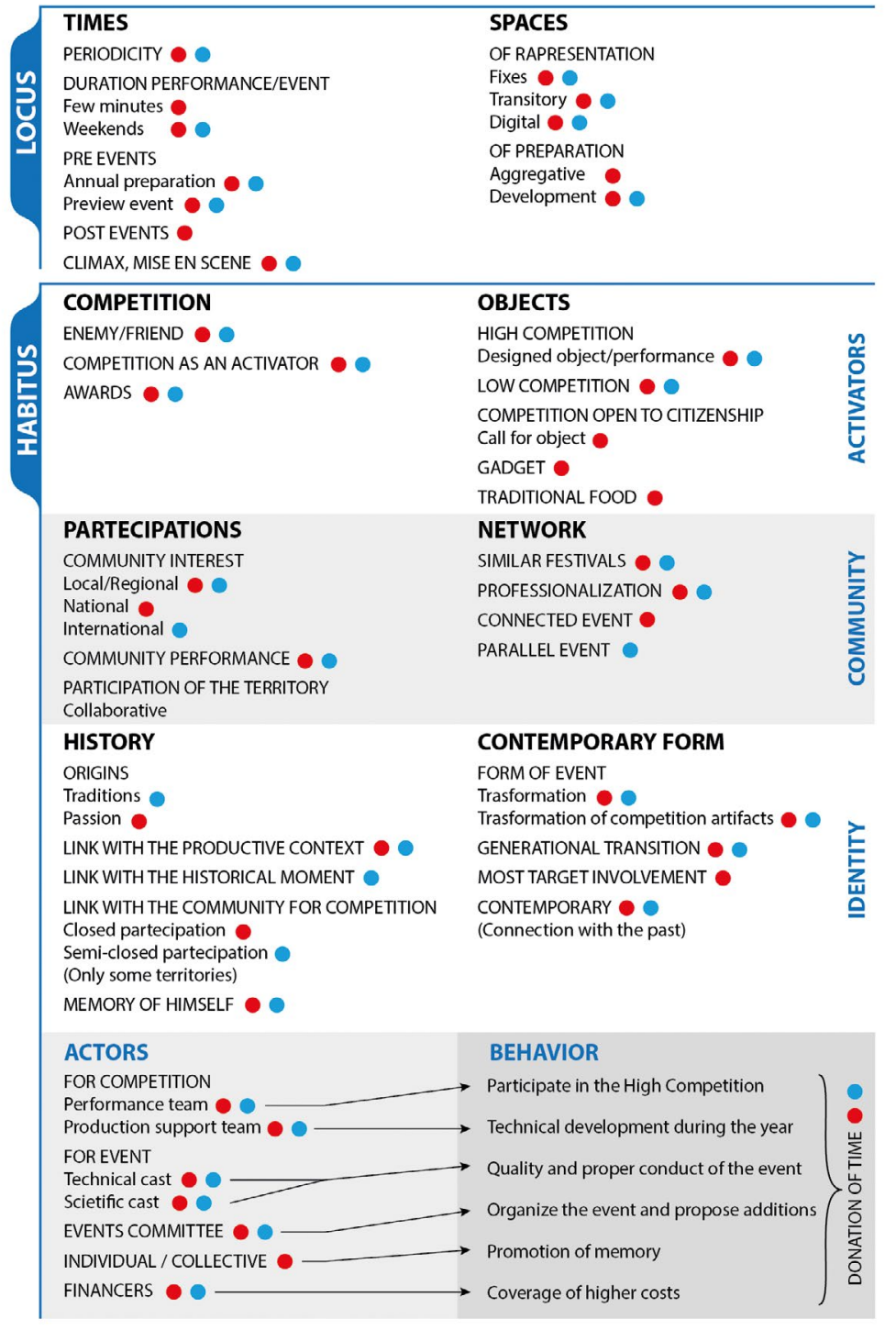

\section{Locus Analysis}

The rhythm at which events occur over time varies from event to event, from people to people (Apolito, 2014, p. 67). During this research, categories were abstracted to understand how time is used. Spontaneous rituals show, from a temporal point of view, similar characteristics; they occur with an annual periodicity and their duration is confined to a very short time: three days for the Carnaval Andino, about ten minutes for the Carrera Autopodistica (Dal Fiume, 2003; Giorgi, 1991).
Fig. 1

Morphological analysis of spontaneous rituals. Reference sources for table development: Choque-Caseres, 2019; Dal Fiume, S. (2003); Municipalidad de Arica (2020); Gladys Huanca, personal interview.

- Carrera Autopodistica - Carnaval Andino 
During the year, these rituals slowly regenerate. The end of the previous event is the preliminary phase, the ruinous destruction of the constructed model and the very absence of the cathartic process of collaboration. Immediately after this voluntary withdrawal from the public and fellow citizens, a sort of transitional phase begins, the most important one: in great secrecy all the teams meet again, in small groups, to design and assemble the vehicles, the floats and the dances for the following year's festival. In the final phase, which we can call post-liminal, there is finally a reintroduction into society: here we experience the proper Mise-en-Scène.

The approach to the Mise-en-Scène is marked by the exponential increase of small public events that mark the arrival of the maximum community participation moment. The temporal structure of the spontaneous rituals analyzed follows models of traditional festivities conceived on the religious calendar, characterized by moments of slowness and waiting (Thackara, 2008, p. 36) or adhering to the seasonal cycles that marked time and work in peasant civilizations (Thackara, 2008, p. 31). From a spatial point of view, spontaneous rituals are quite heterogeneous. They are expressed in the territory in fixed places, the cities in which the Miseen-Scène takes place, and in transitory places, the streets suitable for the use of city movements, which become collective space, culturally given, socially constructed (Durkheim, 2003) where the races and dances redesign the very perception of places.

In the slow preparation, some places acquire importance from an aggregative point of view, others from a collaborative one. The former allows people to enter into relations with already established groups, while in the latter they learn, train, build and experiment.

\section{Habitus Analysis}

The Habitus analysis revealed four macro categories: activators, communities, identities, and actors.

Activators influence the involvement of actors. The main trigger is competition. Objects represent this category since they are at the center of the highest competition (the Carrera vehicles and the dances of the Andean carnival). A long preparation is concentrated in these objects, and they become the representative image of the ritual. Around these elements, other forms of objects are developed, that involve the population in various ways (souvenirs, gadgets, typical food).

The spontaneous rituals analyzed have a well-established history and were chosen for their present vitality. This is proven by the high participation rates of adjacent territories. It is interesting to remark how much the entire population of the territory feels involved in the ritual, regardless of the level of interaction with it. Communities create networks with the surrounding social fabric and with similar events, exchanging ideas and people. 
Origins are the most important element for spontaneous rituals: the history and characteristics that identify the ritual become the object of protection by associations and Institutions. They express deep relationships with the historical, cultural and productive fabric of the territories (e.g. the Bologna mechanical district manifests itself/ emerges in the construction details of the Carrera, the identities of the Andean populations and the opening of borders are expressed in the costumes and dances of the Carnival).

The concept of memory is surrounded by a continuous modifying dynamic that the actors implement on the ritual's elements: spaces, rules, names. These modifications often imply generational transitions and changes in the aggregative and collaborative models between the parties.

Year after year, the process of creating meaning becomes the foundation of the community itself, as "the product of repeated experiences" (Durkheim, 1982, p. 63). This ascendancy permeates the identity of the community as it offers strong evidence of its presence, in time and space, an event that makes the community members what they are.

The individual and the community continuously renegotiate each year their identification with their own place, their own history and ultimately their own self. By accepting to participate, actively or not, in this event, the community is making explicit its approval to a social contract that involves both private and collective spheres.

The category of actors is characterized by multiple levels of involvement. The territorial system that allows the rituality to manifest itself forcefully makes use of explicit figures (such as runners and dancers) and figures in increasingly blurred levels, whose absence can often cause repercussions on the entire collaborative chain. Within the spontaneous rituals the social actors involved use a system in which one donates time and money, receives the relationship with one's community and reciprocates by collaborating in the creation of content, in a similar manner to what used to occur in the earliest indigenous communities (Mauss, 1965, p. 168-172).

\section{Applying the Morphological Model to the CCI Platform Structure}

The use of means of transposition from a morphological model to a model applied to creative collaborative platforms, opens up to a comparison between common categories and different systems, imagining advanced and futuristic designing. (Celaschi et al., 2018). Fig. 2

The platforms where the morphological model has been applied are: Emilia-Romagna Creativa ${ }^{5}$, EC plataforma de economía ${ }^{6}$ creativa, Puglia Creativa ${ }^{7}$. This contribution analyzes platforms that pertain to regional territories, more or less extended, that host the forms of spontaneous rituality investigated and that could express different modes of interaction between $\mathrm{CCl}$.

Emilia Romagna Creativa was born in 2016 as a communication (website) project of the Regional Department of Culture and Landscape of Emilia-Romagna region in Italy and has mainly a showcase function; the tool of radio and podcast allows to create valuable content for all users.
5

www:emiliaromagna-

creativa.it

6

https://ec.cultura.gob.cl 7

www.pugliacreativa.it 


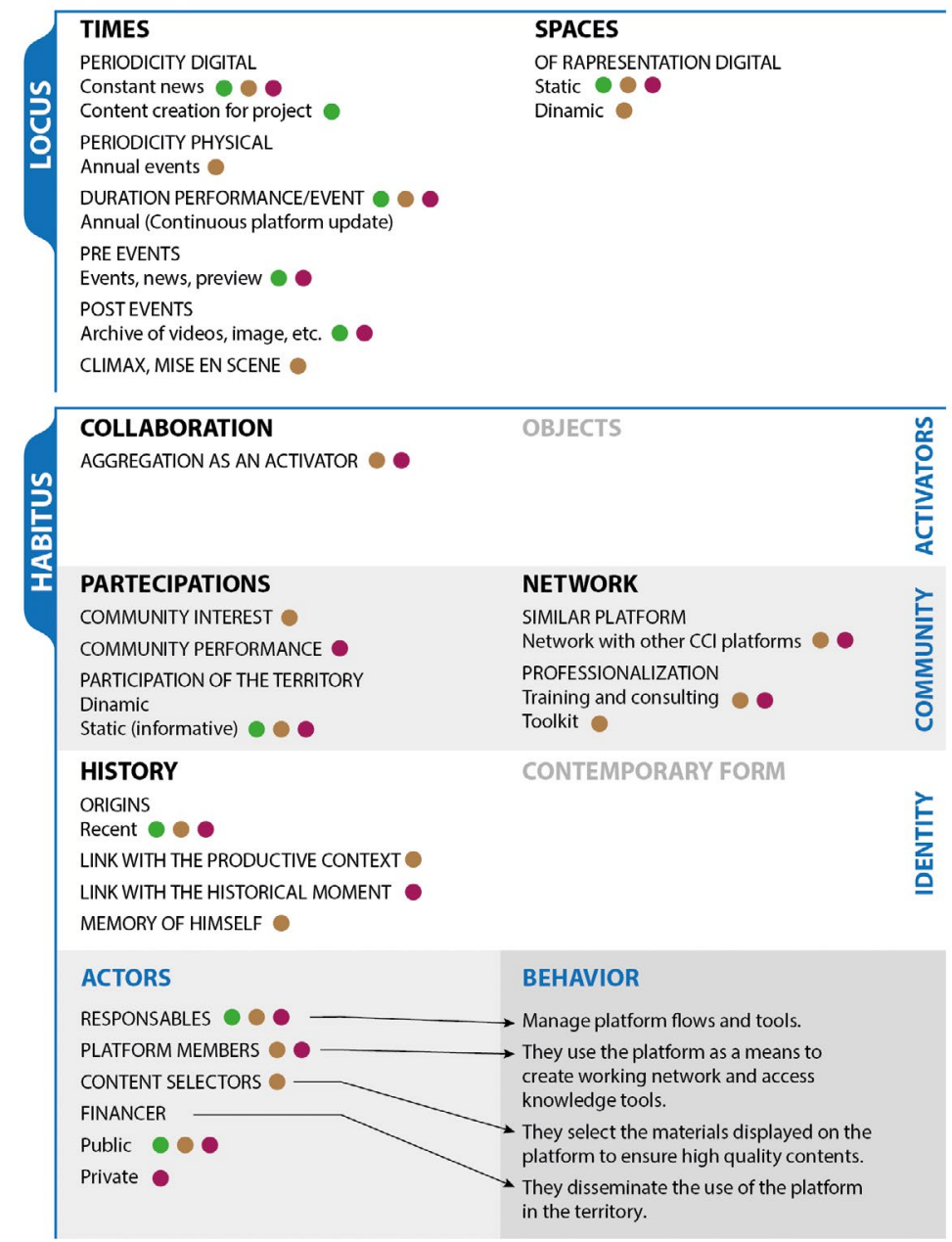

Puglia Creativa, created at the end of 2019, presents itself as a regional cluster for $\mathrm{CCl}$. It offers training services and networking support.

EC plataforma de Economía Creativa, online since November 2020 , addresses a national dimension by capturing aspects of both platforms previously mentioned and in addition proposing annual events dedicated to members.

This reading/comparison highlights four fields in which design cultures can operate: time/rhythm, collaboration/competition, inclusive experience, collaborative ritual and memory.

Those areas design can activate its own tools to make $\mathrm{CCl}$ platforms digital communities with time space and rituals who compenetrate within a virtual/real context.
Fig. 2

Applying the morphological model of spontaneous rituals to the $\mathrm{CCl}$ platform structure. Reference sources for table development: Cinzia Lagioia, Director of the Creative Puglia District, personal interview; websites platform.

- Emilia-Romagna Creativa

- EC plataforma de economía creativa

- Puglia Creativa 
The events Carrera Autopodistica and the Andean Carnival take place once a year. The moments of waiting and preparation are long, the frequency of activities increases exponentially, leading to the Mise-en-Scène. During the waiting period, the actors strengthen their relationships by devoting a lot of time to the collaboration in the common project.

Rituals follow the time of events, marked by natural rhythms linked to seasonality (Thackara, 2008, p. 36).

In platforms, the temporal dynamic is designed in relation to communication and underlies the algorithmic logic of the Internet. In these platforms, the objectification of time is clearly at work (Dorfles, 2003, p. 105), through the measurability of the actions that data allow to perform on it. Time is thus used with regular high-frequency rhythms far from the real condition (Zannoni, 2018) on which the inner and relational body was formed.

\section{Collaboration in Competition}

In the spontaneous collective practices, competition plays a triggering role on the citizens' participation, leading them to collaborate on several levels.

In $\mathrm{CCl}$ platforms, on the other hand, competition is never explicitly stated: they operate narratives linked to the word aggregation.

\section{Inclusive Experience}

Spontaneous rituals include the participation of the population at all levels. Everyone can participate in a changing and coherent biographical process that is fueled by different frames and momentary identities (Bercelli, 2004, p. 85). Through spontaneous manifestations (customs, goods, food) other actors can take part in the rituals and/or create new content. The analyzed platforms do not allow the bottom-up aggregation of content.

\section{Collaborative Rituals and Memory}

The memory of rituals is embedded in things, space and people through collaborative narratives/relationships born from transformations of community space, emotions and experiences lived together, and from the sharing of identity objects. An emotional tension between memory and identity that is partly linked to the relationship with artifacts (Maldonado, 2015, in Zannoni 2018, p.145).

Within platforms, relationships are stimulated through knowledge constrained in galleries of projects and guided matching moments; memory is based on archives of recorded data, videos, texts and images.

Therefore, the $\mathrm{CCI}$ digital space can be a fertile ground for developing these characteristics, following what increases engagement within bottom-up collective rituals. Fig. 3 


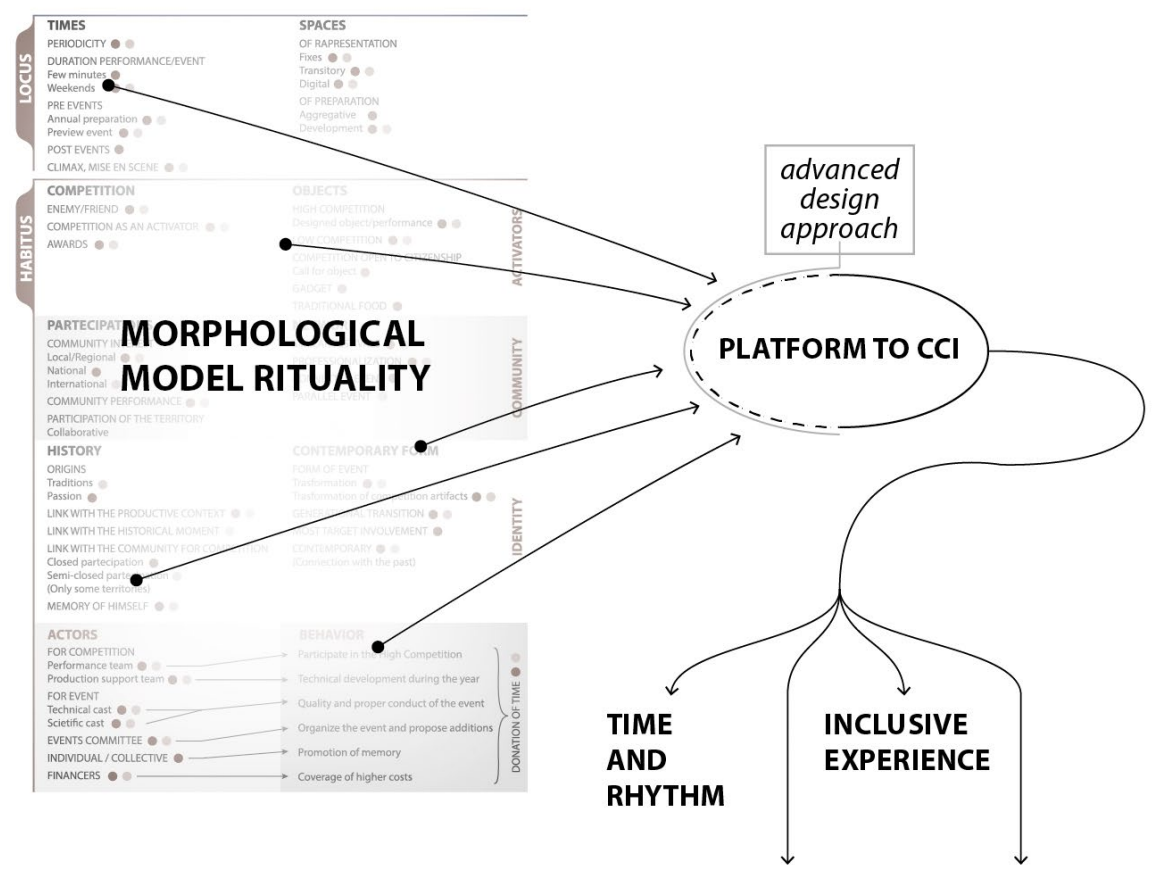

COLLABORATION IN COMPETITION

Concerning the analyzed platforms, the approach proposed by Advanced Design is to generate scenarios on multiple levels:

- activate bottom-up systems internal to the platform, allowing the community to express and be actively part of the process.

- to shape a "ritual" flow, where each output is linked to the other through a narrative and factual connection. support the creation of a virtual community by strengthening identity values during events, in space and time and methods designed to work on the collective memory.

\section{Conclusions}

The analysis of spontaneous rituals has shown how complex is to conceive interactive design processes able to:

- last over time, also involving civil society and professionals in the development of new forms of entrepreneurship, products or services,

- $\quad$ stimulate a collaborative process that makes the territorial ecosystem involved on different levels.

The application of the morphological model of spontaneous rituals to the structure of the $\mathrm{CCl}$ platforms reveals divergences in the implementation of certain categories within the projects. 
These differences, in the use of time and space, narrative forms, use of memory, processes of donation and collaboration, constitute the set of fundamental design guidelines for intervening in the platforms, linking the experiences they propose with individual, communities and territorial identities.

Some of the emerged characteristics reveal a design that is ready for use, while others are situated in a horizon of anticipation and advanced design (Celaschi et al., 2018), within scenarios in which digital languages have embraced temporalities and relational modes closer to human ritual dynamics.

\section{Acknowledgement}

An acknowledgement to Giorgio Dall'Osso, Ph.D. (Alma Mater Studiorum - Università di Bologna) who supported us in the development of the research.

\section{Elena Alfaro}

Designer (Universidad Católica de Chile) and Journalist (Universidad de Santiago de Chile). Programa de Artesanía UC Director. She has developed her career in the area of collaboration between crafts and design, in which she had developed extracurricular, teaching and research projects.

\section{Pietro Gamberini}

With a five-year degree in Anthropology, a three-year degree in Humanities

(Alma Mater Sturiorum - Università di Bologna, Brunel University, UNAM), and work/field research in Puebla (Mexico), Estoril (Portugal) and Nairobi (Kenya), he is now studying for a Ph.D. in the Department of Studies on Language and Culture (Università degli Studi di Modena e Reggio Emilia).

\section{Laura Succini \\ Architect with experience in strategic design for development of project that links territory, manufactu- ring and creativity. She is Ph.D. student at Alma Ma- ter Studiorum - Università di Bologna, she researches design and collaborative approach within territories and design for responsible innovation. Since 2018 she is a member of the Advan- ced Design Unit, the design research group of the Department of Architecture — Università di Bologna.}


Apolito, P. (2014). Ritmi di festa. Corpo, danza, socialità. II Mulino.

Bercelli, F. (2004). Identità e narrazione: di sé e di altri. In Lorenzetti R., Stame S. (Eds.), Narrazione e identità. Aspetti cognitivi e interpersonali (pp. 83-109). GLF editori Laterza.

Béraud, P., du Castel, V., \& Cormerais, F. (2012). Open innovation, economy of contribution and the territorial dynamics of creative industries. Journal of Innovation Economics, 10(2), 81.

Bortolotto, C. (2010). Addio al territorio? Nuovi scenari del patrimonio culturale immateriale. LARES, 3 , 355-373.

Boschma, R. (2005). Proximity and Innovation: A Critical Assessment. Regional Studies, 39(1), 61-74.

Carayannis, E. G., Barth, T. D., \& Campbell, D. F. (2012). The Quintuple Helix innovation model: Global warming as a challenge and driver for innovation. Journal of Innovation and Entrepreneurship, 1(1), 2.

Celaschi, F., Formia, E., \& Franzato, C. (2018).

Ritorno al futuro. II fattore tempo e i futures studies nell'approccio design driven all'innovazione. DIID. Disegno Industriale Industrial Design, 64, 126-133.

Casals, M., Errázuriz, M., Pfeiffer, E. (2018). Arica Y Camarones. Relatos Turísticos Patrimoniales. Ediciones Universidad Central de Chile.
Chamorro, A. (2010). Danzar el Carnaval Andino en Arica: cuerpos y expresión festiva. VII Congreso Chileno de Antropología. Colegio de Antropólogos de Chile A. G, San Pedro de Atacama. https://www.aacademica. org/vii.congreso.chileno. de.antropologia/50.pdf

Chamorro, A. (2013). Carnaval Andino en la ciudad de Arica: performance en la frontera norte chilena. Estudios Atacameños. Arqueología y Antropología Surandina, (45), 41-54.

Choque-Caseres, D. (2019). ¿Indígenas transnacionales o nacionales? Tensiones entre el Carnaval Andino de Arica y el desarrollo turístico en la frontera. Antropologías del Sur, 6(12), 241-260, 241-260.

Dal Fiume, S. (2003). Mezzo secolo di Carrera (Biblioteca Comunale Castel San Pietro Terme).

Dorfles, G. (2003). Nuovi riti, nuovi miti. Skira.

Durkheim, E. (with Lukes, S.). (1982). The rules of sociological method (1st American ed). Free Press. (Original work published 1895).

Durkheim, É. (2008). The

Elementary Forms of Religious Life (C. Cosman, \& M. S. Cladis, Eds). Oxford University Press. (Original work published 1912).

Geertz, C. (1973). The interpretation of cultures: selected essays. Basic Books.
Giorgi, G. (1991). Carrera: storie di vetture senza motore azionate a spinta.. umana per le vie di Castel San Pietro Terme, Sala Cassero, mostra dal 1 al 29 settembre 1991. Calderini.

Maldonado, T. (2005). Memoria e conoscenza. Sulle sorti del sapere nella prospettiva digitale. Feltrinelli.

Mauss, M. (with Lévi-Strauss, C). (1965). Teoria generale della magia e altri saggi. Einaudi. (Original work published 1923-24).

Municipalidad de Arica. (2020). Bases de participación versión XIX del Carnaval Andino Internacional de Arica con la Fuerza del Sol. Decreto 769/ 20 de enero de 2020.

Municipalidad de Arica. (2020). Dossier de prensa 2020. XIX versión del Carnaval Andino con la Fuerza del Sol, Arica.

Nonaka, I. (1994). A Dynamic Theory of Organizational Knowledge Creation. Organization Science, 5(1), 14-37.

Pils, G., \& Trocchianesi, R. (2017). Design e rito. La cultura del progetto per il patrimonio rituale contemporaneo. Mimesis.

Santoro, G., Bresciani, S., Papa, A. (2020). Collaborative modes with Cultural and Creative Industries and innovation performance: The moderating role of heterogeneous sources of knowledge and absorptive capacity. Technovation, 92 93, 102040.
Schiuma, G., \& Lerro, A. (2014). Do cultural and creative industries (cci) matter for innovation and value creation in knowledge-based business? Aims, forms and practices of collaboration in Italy. Knowledge-Based Services. 7th Knowledge Cities World Summit, Tallinn, Estonia.

Scodeller, D. (2017). Design spontaneo. Tracce di progettualità diffusa. Corraini Edizioni.

Sedini, C. (2018). Collaborare per competere. In M. Parente \& C. Sedini (Eds.), D4T Design per i Territori. Approcci, metodi, esperienze. (pp. 210-213). Design Experience, LISt Lab.

Thackara, J. (2008). In the bubble. Design per un futuro sostenibile. Allemandi.

United Nations Development Programme and UNESCO (2013). Creative Economy Report 2013 Special Edition: Widening local development pathways. UNDP, UNESCO. http:// www.unesco.org/culture/ pdf/creative-economy-report-2013.pdf

Zannoni, M. (2018). Progetto e interazione. I/ design degli ecosistemi interattivi. Quodlibet. 